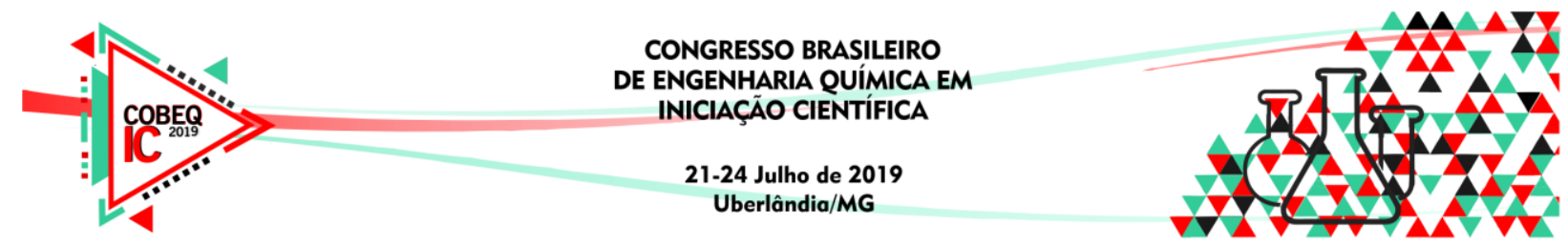

\title{
RECUPERAÇÃO DE METAIS ATRAVÉS DA BIOLIXIVIAÇÃO DE BATERIAS DE ÍONS DE LÍTIO UTILIZANDO Acidithiobacillus thiooxidans
}

\author{
G. H. S. MOURA ${ }^{1}$, L. M. MESQUITA ${ }^{1}$, L. H. R. MENÊZES ${ }^{1}$, M. M. RESENDE ${ }^{1}$, J. S. \\ FERREIRA $^{1}$ \\ ${ }^{1}$ Universidade Federal de Uberlândia, Faculdade de Engenharia Química \\ E-mail para contato: guilhermevazante@ hotmail.com
}

\begin{abstract}
RESUMO - A recuperação de cobalto e lítio das baterias de íons de lítio (LIBs) utilizadas tem atraído atenção mundial devido a problemas de impactos ambientais e de fornecimento de recursos, já que o custo de obtenção desses metais é alto. $\mathrm{Na}$ busca por novos métodos de recuperação do $\mathrm{Li}$ e $\mathrm{Co}$, a biolixiviação vêm se destacando, por apresentar uma abordagem econômica e de baixo impacto ambiental. O objetivo desse trabalho foi a aplicação do Acidithiobacillus thiooxidans para biolixiviar esses metais de LIBs usadas, que após análise dos resultados, mostrou-se uma forma promissora de recuperação de cobalto e lítio, recuperando $86 \%$ de Lítio (1,68 vezes maior que o meio sem inóculo) e $37 \%$ de Cobalto (5,28 vezes maior que o meio sem inóculo).
\end{abstract}

\section{INTRODUÇÃO}

Nas últimas décadas houve um aumento da utilização de aparelhos eletrônicos, fazendo com que a produção desse tipo de equipamentos figure entre os setores industriais que tem os maiores índices de crescimento na atualidade. Impulsionado pela inovação tecnológica e constantes mudanças nos padrões de consumo, o descarte de resíduos no meio ambiente provenientes desses aparelhos, como as baterias de íons de lítio tornou-se um problema (Schwarzer et al., 2005). Além disso, entre outros componentes, as LIBs possuem metais pesados (Lítio e Cobalto) que em contato com o ser humano, direta ou indiretamente, afetam o sistema nervoso central e podem ser causa de doenças pulmonares, respiratórias e até mesmo oncológicas (Guimarães et al., 2000).

Em 2017 35\% da produção global de lítio era usada na fabricação de LIBs (Swain, 2017). Estima-se que, se o lítio não for reciclado, o mundo enfrentará uma grave escassez de lítio entre o ano de 2021 e 2023. Ademais, 25\% da produção global de cobalto é usada na fabricação de LIBs. Ao reciclar e reutilizar os materiais LIB, ocorre uma redução no uso de recursos naturais e no consumo de energia (Santana et al., 2017). 


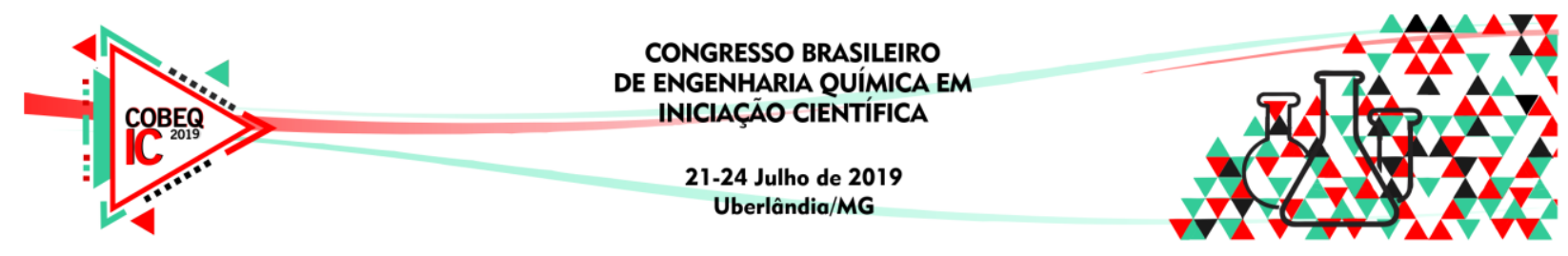

As metodologias aplicadas atualmente para recuperar metais das LIBs são: Pirometalurgia, no qual há liberação de gases perigosos, um alto consumo de energia, bem como perdas de metais valiosos, a hidrometalurgia que está associada a riscos ambientais devido ao uso de reagentes tóxicos para lixiviar metais e uma grande quantidade de subprodutos gerados e a biolixiviação que é um processo que utiliza a atividade de microrganismos para recuperar metais que apresenta menores exigências de mão-de-obra e energia, menor investimento de capital e menores riscos, apesar de proporcionar uma cinética lenta (Lauffer, 2000).

Neste contexto, faz-se necessário aprimorar os meios de recuperação dos metais com o intuito de otimizar o processo e reduzir custos. Uma alternativa é apresentada nesse trabalho utilizando Acidithiobacillus thiooxidans, que é uma bactéria acidófila capaz de oxidar o enxofre elementar como doador de elétrons na cadeia de transporte de elétrons e gerar ácido sulfúrico e como resultado baixar o pH meio, para recuperação de Lítio e Cobalto nas LIBs.

\section{METODOLOGIA}

As baterias foram desmanteladas manualmente em capela de exaustão, com o auxílio de alicates e equipamentos de segurança individual (DORELLA e MANSUR, 2007). Os principais componentes como plástico externo, carcaça metálica, plástico interno, lâmina de alumínio (suporte do ânodo), lâmina de cobre (suporte do cátodo, que contém óxidos de Li e Co) e lâmina de copolímero foram separados manualmente. Após o desmantelamento, o cátodo e o ânodo foram separados dos demais componentes da bateria e triturados em partículas menores utilizando um moinho de martelo.

As bactérias Acidithiobacillus thiooxidans usadas no ensaio de biolixiviação, foi doada pela Departamento de Bioquímica e Tecnologia Química (Laboratório de Biohidrometalurgia) da Universidade Estadual Paulista "Júlio de Mesquita Filho"- Campus Araraquara/SP. A cultura foi cultivada em meio 9K, com composição apresentada na Tabela 1.

Tabela 1- Composição meio de cultura 9K para manutenção do A. thiooxidans (SILVERMAN; LUNDGREN, 1959).

\begin{tabular}{cc}
\hline Reagente & Concentração (g/L) \\
\hline$\left(\mathrm{NH}_{4}\right)_{2} \mathrm{SO}_{4}$ & 3,0 \\
$\mathrm{MgSO}_{4}$ & 0,5 \\
$\mathrm{KH}_{2} \mathrm{PO}_{4}$ & 0,5 \\
$\mathrm{KCl}$ & 0,1 \\
\hline
\end{tabular}




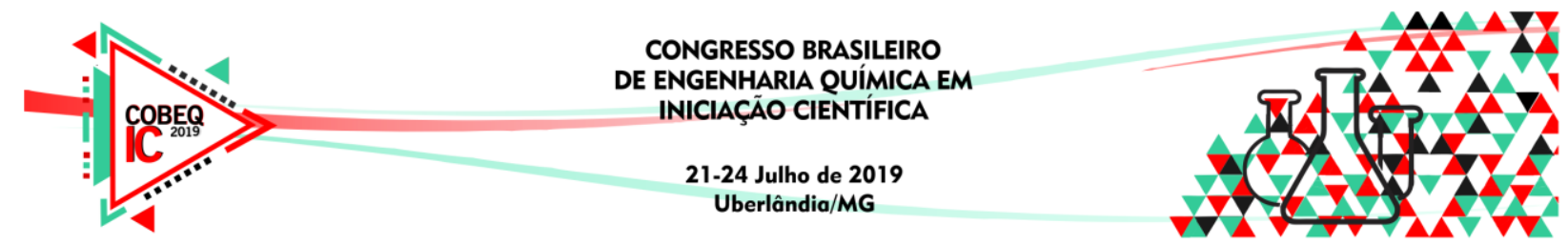

O meio $9 \mathrm{~K}$ contém os sais necessários ao crescimento do microrganismo e enxofre elementar utilizado como fonte de energia pelo A. thiooxidans. $\mathrm{O} \mathrm{pH}$ do meio foi ajustado em 2,8 com adição de $\mathrm{H}_{2} \mathrm{SO}_{4}(0,5 \mathrm{M})$. Para cultivo dos microrganismos foi utilizado uma concentração de inóculo de $10 \%(\mathrm{v} / \mathrm{v})$ incubados à $30^{\circ} \mathrm{C}$ em uma estufa. A manutenção ocorria a cada 21 dias, aproximadamente.

Para os ensaios de biolixiviação foram utilizados erlenmeyer de $250 \mathrm{~mL}$ com $90 \mathrm{~mL}$ de meio basal Tabela 1 devidamente fechados com rolhas de algodão e gaze e esterilizados em autoclave por 20 minutos a 1 atm e $121^{\circ} \mathrm{C}$ e $10 \mathrm{~mL}$ de inóculo com concentração inicial de $10^{7}$ células/mL medida por câmara de Neubauer. A avalição do crescimento do $A$. thiooxidans é sútil sendo a diminuição do $\mathrm{pH}$ do meio o principal indício de crescimento, caindo de 2,8 para próximo de 1 . Então adicionou-se $0,5 \mathrm{~g}$ da amostra contendo os eletrodos ( $5 \mathrm{~g} / \mathrm{L}$ de razão sólido/líquido). A biolixiviação foi realizada em frascos de sacrifício e para controle avaliouse o pH, a concentração de Co e Li por EAAC (Espectroscopia de Absorção Atômica).

\section{RESULTADOS E DISCUSSÃO}

A biolixiviação empregando o Acidithiobacillus thiooxidans foi avaliada utilizando ambos os eletrodos, após 21 dias de crescimento do microrganismo com uma concentração inicial de $10 \mathrm{~g} / \mathrm{L}$ de enxofre como fonte de energia e pH 1 . Na Figura 1, estão apresentados os resultados do ensaio utilizando uma razão sólido/líquido de 5/L, $180 \mathrm{rpm}$ durante 28 dias. O experimento foi realizado em paralelo com o ensaio controle, sem o inóculo.

Figura 1 - Recuperação de metais (a) Lítio, ( $)$ com inóculo ( $\square$ ) sem inóculo, e (b) Cobalto, (•) com inóculo (०) sem inóculo, utilizando A. thiooxidans (razão S/L de $5 \mathrm{~g} / \mathrm{L}$ da amostra contendo os eletrodos, $180 \mathrm{rpm}$ )
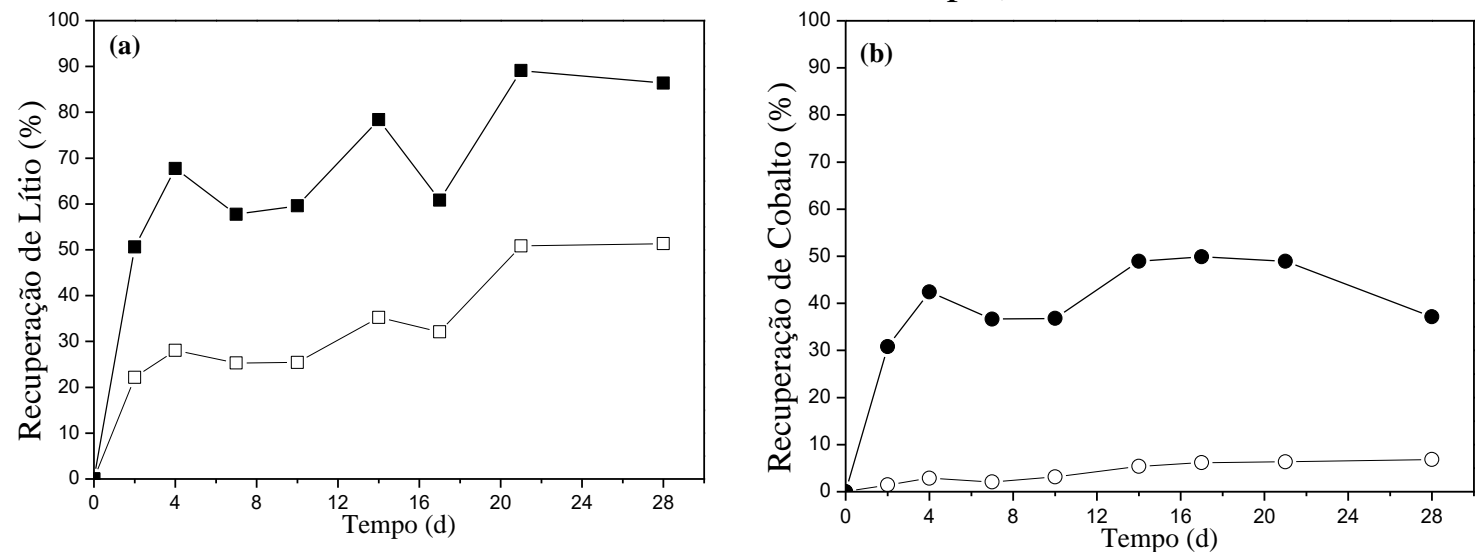

A partir da análise da Figura 1 (a), nota-se que a dissolução de aproximadamente $70 \%$ do Li no meio lixiviante aconteceu nos primeiros 5 dias. A amostra controle dissolveu o lítio com uma cinética mais lenta. Assim para o Li, a recuperação final foi de 86\%, 1,68 vezes maior que a amostra sem inóculo. Enquanto isso na Figura 1 (b), a biolixiviação do Co ocorreu até o $13^{\circ}$ dia, apresentando um valor final de 37\%, 5,28 vezes superior à amostra controle, manteve-se constante após o dia 4. 


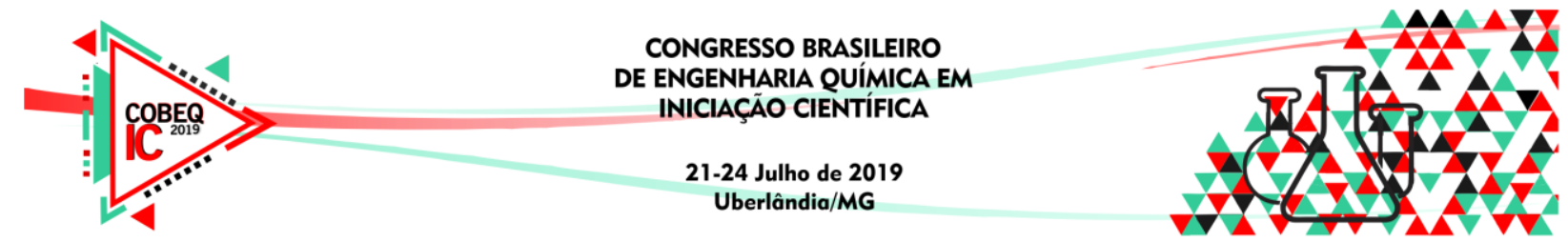

A variação do $\mathrm{pH}$ ao longo do ensaio de biolixiviação com o A. thiooxidans é apresentado na Figura 2. Nota-se um aumento do $\mathrm{pH}$ com o andamento do teste, contudo é mais acentuado para a amostra com inóculo mantendo-se aproximadamente em 2,63, que é o pH próximo ao inicial do cultivo do microrganismo. Além disso, assim como há a produção de ácido sulfúrico é justificável a manutenção do $\mathrm{pH}$ mesmo enquanto é consumido para dissolução dos metais.

Figura 2 - Variação do pH ((口) sem inóculo (ロ) com inóculo) ao longo do tempo de biolixiviação, utilizando $A$. thiooxidans (razão S/L de $5 \mathrm{~g} / \mathrm{L}$ dos eletrodos, $180 \mathrm{rpm}$ )

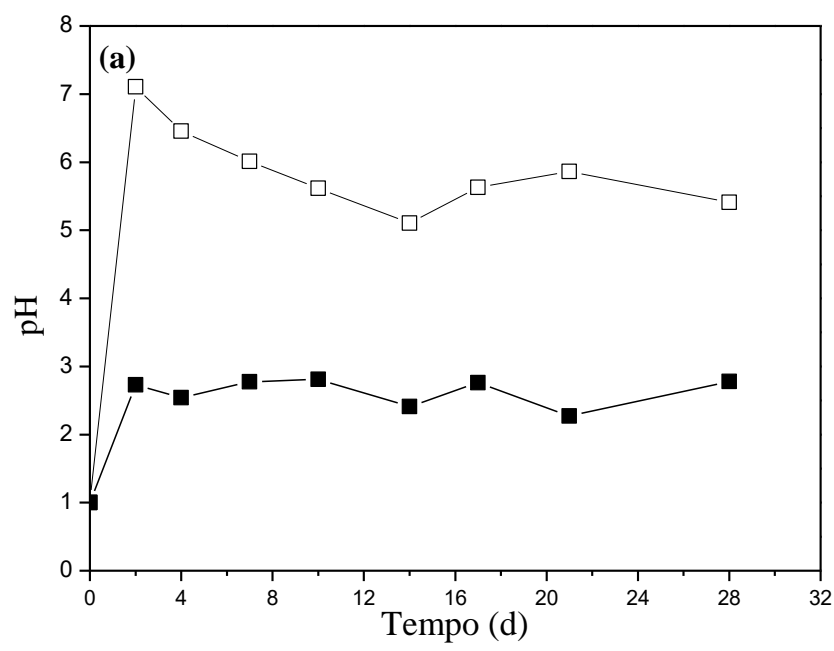

Em comparação com estudos anteriores, Xin et al. (2016) avaliaram a recuperação de metais valiosos como Li e Co de baterias de íons de lítio com uma densidade de polpa de 1 g/L. Os resultados mostraram a eficiência máxima de extração de Li foi de $98 \%$ com Acidithiobacillus thiooxidans sem adaptação do microrganismo. Apesar de apresentar resultados superiores em relação a porcentagem dos metais recuperados, a quantidade de amostra utilizada no presente estudo foi 5 vezes maior.

\section{CONCLUSÃO}

Neste trabalho, o potencial do Acidithiobacillus thiooxidans foi comprovado, com resultados promissores em processos de biolixiviação de Li e Co, tendo uma recuperação final de Lítio de $86 \%$ e de $37 \%$ em cobalto, 1,68 vezes maior e 5,28 vezes superior que a amostra sem inóculo, respectivamente, em baterias de Íons de Lítio. Novos estudos podem ser realizados para obter uma quantidade maior de recuperação, visto que trabalhos anteriores apesar de utilizar uma razão sólido/líquida inferior, obteve resultados superiores. Assim, como o objetivo principal é a obtenção máxima de ambos os metais, uma alternativa para o processo de biolixiviação com o A. thiooxidans é ser testado em condições diferentes. 


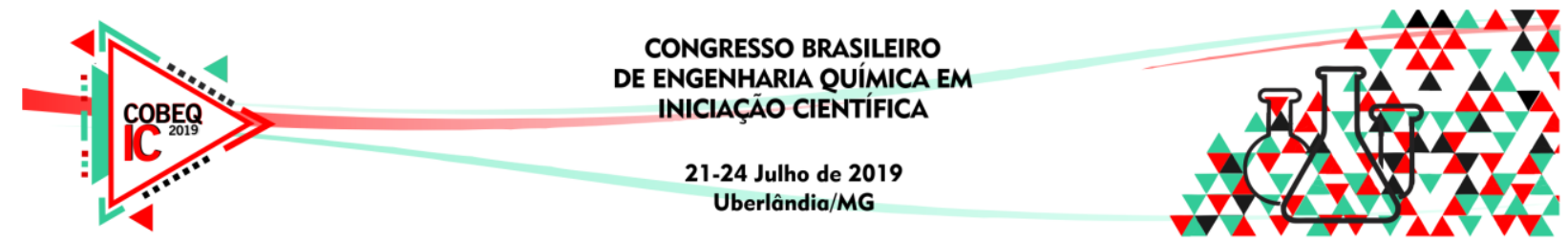

\section{AGRADECIMENTOS}

Os autores agradecem a UFU, FAPEMIG, CNPq e CAPES pelo apoio financeiro.

\section{REFERENCIAS}

DORELLA. G.; MANSUR, M. B.; A study of the separation of cobalt from spent Li-ion battery residues. Journal of Power Sources., v. 170 p. 210-215 (2007).

FERNANDES, R. G. Estudo de técnicas de recuperação de metais de resíduos de equipamentos eletroeletrônicos. 80f. Trabalho de Graduação - Escola de Engenharia de São Carlos, Universidade de São Paulo, São Paulo, 2014.

G1 (2017), "Mundo produz 44,7 milhões de toneladas de lixo eletrônico, diz relatório", Disponível em: https://g1.globo.com/natureza/noticia/mundo-produz-447-milhoes-detoneladas-de-lixo-eletronico-diz-relatorio.ghtml. Acessado em: 31 de março de 2019.

IBGE - Instituto Brasileiro de Geografia e Estatística. Censo 2010 de Frederico Westphalen RS. Disponível em: http://www.ibge.gov.br/cidadesat/topwindow.htm?1. Acessado em: 12/02/2012. LAUFFER, L. G. Anais do Seminário sobre Reciclagem de Resíduos Industriais, Companhia de Tecnologia de Saneamento Ambiental, São Paulo, Brasil, 2000 .

SANTANA, I. L.; MOREIRA, T. F. M.; LELIS, M. F. F.; FREITAS, M. B. J. G. Photocatalytic properties of $\mathrm{Co} 3 \mathrm{O} 4 / \mathrm{LiCoO} 2$ recycled from spent lithium-ion batteries using citric acid as leaching agent. Materials Chemistry and Physics, v. 190, p. 38-44, 2017.

SCHWARZER, Stefan et al. E-waste, the hidden side of IT equipment's manufacturing and use. In: 2005. https://archive-ouverte.unige.ch/unige:23132

SILVERMAN, M. P.; LUNDGREN, D. G. Studies on the chemoautotrophic iron bacterium Ferrobacillus ferrooxidans. I. An improved medium and a harvesting procedure for securing high cell yields. Journal of Bacteriology, v. 77, n. 5, p. 642-647, 1959.

SWAIN, B. Recovery and recycling of lithium: A review. Separation and Purification Technology, v. 172, p. 388-403, 2017.

VIEIRA, J. L.; GUIMARÃES. G. A. Aspectos Ambientais e Toxicológicos dos Metais Pesados. SEPAT-PA. 15 e 16 de dezembro de 2000. Apostila do Curso Aspectos Ambientais e Toxicológicos dos Metais Pesados.

XIN, Y.; GUO, X.; CHEN, S.; WANG, J.; WU, F., XIN, B. Bioleaching of valuable metals $\mathrm{Li}, \mathrm{Co}, \mathrm{Ni}$ and $\mathrm{Mn}$ from spent electric vehicle Li-ion batteries for the purpose of recovery. Journal of Cleaner Production, v. 116, p. 249-258, 2016. 